\title{
IMPLEMENTASI LAYANAN APLIKASI BERGERAK UNTUK INFORMASI WISATA PROVINSI PAPUA BARAT
}

\author{
Parma Hadi Rantelinggi* $^{*}$, Arnita Irianti ${ }^{2}$, Dwi Aryanto ${ }^{3}$ \\ 1,3 Program Studi Teknik Informatika, Universitas Papua, Manokwari \\ ${ }^{2}$ Program Studi Teknik Informatika, Universitas Sulawesi Barat, Majene \\ Email: 12.rantelinggi@unipa.ac.id, ${ }^{2}$ arnitairianti@unsulbar.ac.id, ${ }^{3}$ dwi.inter08@gmail.com \\ *Penulis Korespondensi
}

(Naskah masuk: 31 Agustus 2019, diterima untuk diterbitkan: 07 Oktober 2020)

\begin{abstract}
Abstrak
Provinsi Papua Barat memiliki beragam tempat pariwisata. Namun, sebagian masyarakat Indonesia yang berkunjung ke Papua Barat hanya mengenal Raja Ampat sebagai tempat wisata. Padahal masih banyak tempat yang belum dikenal secara luas untuk menjadi tujuan wisata. Selain itu, belum adanya aplikasi yang berbasis Android yang dapat mendukung dalam promosi pariwisata di Papua Barat. Penelitian ini bertujuan untuk merancang dan membangun aplikasi bergerak agar dapat dimanfaatkan sebagai sarana melakukan promosi wisata. Penelitian ini berkontribusi pada penduduk untuk mengakses informasi tentang lokasi wisata di Provinsi Papua Barat secara tepat dan mudah. Penelitian ini menggunakan model Design Science Research (DSR) merupakan model yang bisa difungsikan sebagai solusi untuk membangun dan mengevaluasi jejak digital secara waktu nyata, melibatkan variabel yang mempertimbangkan desain, utilitas desain dan menentukan karakter variabel yang dievaluasi. Aplikasi yang dibangun berbasis Android dengan memanfaatkan layanan cloud PaaS serta layanan google maps dalam mempermudah mencari lokasi wisata. Evaluasi akhir yang lakukan dilihat dari hasil penyebaran kuesioner kepada responden untuk tingkat kepuasan pemanfaatan aplikasi yang dibangun. Hasil menyatakan 36,9\% responden sangat setuju, 51,6\% menyatakan setuju, 10,3\% menyatakan cukup dan 1,2\% menyatakan kurang. Sehingga diketahui mayoritas responden setuju apabila aplikasi ini dapat digunakan sebagai alat untuk promosi dan mencari informasi pariwisata di Provinsi Papua Barat
\end{abstract}

Kata kunci: aplikasi bergerak, DSR, Papua Barat, ponsel cerdas, promosi wisata

\section{IMPLEMENTATION OF MOBILE APPLICATION SERVICE FOR TOURIST INFORMATION IN PAPUA BARAT PROVINCE}

\begin{abstract}
Papua Barat Province has various tourist attractions. However, even Indonesians who visited Papua Barat only know Raja Ampat as a tourist destination. The fact is, there are still many places that are unknown to the general public. Beside that, there is no Android-based application that can support tourism promotion in Papua Barat. This research aims to design and build a mobile application to promote tourism. This research contributes to the population by providing precise and easy access to information about tourist sites in Papua Barat Province. This research used The Design Science Research (DSR) model which is a model that can function as a solution for building and evaluating digital trace in real-time, involves variables that consider the design, utility design and determine the character of the variables evaluated. The application is Android-based, utilizing the PaaS cloud service as well as the Google maps service for making it easier to find tourist sites. The final evaluation is seen from the results of the questionnaires distributed to respondents to find out their level of satisfaction of the application. The results show that 36.9\% of respondents strongly agreed, 51.6\% agreed, 10.3\% said fair, and $1.2 \%$ said less. So it is known that the majority of respondents agreed that this application can be used as a tool for promoting and searching for tourism information in Papua Barat Province.
\end{abstract}

Keywords: mobile application, DSR, Papua Barat, smartphones, tourist promotion

\section{PENDAHULUAN}

Lebih dari dua dekade teknologi informasi seperti teknologi jaringan nirkabel yang telah dirasakan manfaatnya bagi sektor industri (Rantelinggi \& Djanali, 2015; Rantelinggi, Paiki \& Rantelobo, 2017), sebagai contoh penerapan 
teknologi nirkabel di sektor industri yaitu Bluetooth Low Engergy yang dimanfaatkan untuk membantu navigasi indoor dan pengembangan bandara cerdas. Selain itu salah satu perangkat teknologi informasi yang digunakan di sektor industri adalah ponsel cerdas yang beroperasi menggunakan Android sebagai sistem operasi utama (Shihab \& Murtadho, 2011). Ponsel cerdas ini dapat membantu penggunanya untuk mencari tempat wisata yang dekat dengan tempat tinggal mereka.

Wisata bisa merupakan objek di alam terbuka, bisa pula dalam bentuk bangunan seperti museum, benteng dan situs peninggalan masa lampau yang mempunyai nilai. Indonesia salah satu negara yang menjadi tujuan wisata, salah satunya adalah di Provinsi Papua Barat.

Papua Barat merupakan salah satu provinsi di pulau Papua yang terkenal dengan Raja Ampat. Padahal masih banyak wilayah yang menjadi destinasi pariwisata. Sehingga perlunya penelitian dalam mendukung promosi destinasi wisata di Papua Barat. Kontribusi dalam penelitian ini adalah aplikasi mobile yang dirancang dan dibangun dapat memberikan ketepatan dan kemudahan bagi wisatawan yang ingin mencari lokasi wisata di Provinsi Papua Barat. Aplikasi dapat memberikan gambaran lokasi yang menjadi tujuan destinasi wisata. Hal ini agar wisatawan dapat memperoleh gambaran awal sebelum mengunjungi tempat wisata tersebut.

Perangkat yang dibangun berbasis Android menggunakan layanan Cloud Platform as a Service (PaaS) dan layanan Google Maps agar mudah mencari spot wisata secara waktu nyata. Selain itu memanfaatkan Google Maps sehingga ketepatan dalam mengakses lokasi wisata bisa tercapai. Dalam penelitian ini diimplementasikan sebuah metode yaitu Design Science Research (DSR) (Gregor \& Hevner, 2013). DSR adalah sebuah metode yang berfungsi untuk mengidentifikasi kebutuhan, solusi dan evaluasi (Agustina \& Achmad, 2019).

Tahapan yang dibahas dalam artikel ini secara struktur sebagai berikut. Bagian 2 memberikan penjelasan pustaka yang dipakai dalam penelitian ini. Bagian 3 membahas metode penelitian yang digunakan, hasil dari konsep yang diusulkan dan pembahasannya dijelaskan pada bagian 4 . Kesimpulan dari hasil penelitian dalam artikel ini pada bagian 5 .

\section{METODE PENELITIAN}

Dalam tahapan ini di diskusikan mengenai aplikasi yang dibangun beserta pembahasan berdasarkan metode yang di pakai yaitu DSR. Telah banyak penelitian yang terbantu dengan model metode DSR yang menyajikan pedoman penelitian mulai dari yang sederhana hingga yang kompleks. Perancangan penelitian dengan pola DSR disusun dalam tujuh tahap sebagai berikut :
1. Pendahuluan

Tujuan penelitian yaitu memudahkan akses informasi dan mempromosikan lokasi pariwisata Provinsi Papua barat.

\section{Studi Literatur}

Bagian ini memberikan penjelasan mengenai Literatur yang sebelumnya termasuk artefak yang telah dipakai untuk memecahkan persoalan yang sama.

3. Metode

Penelitian ini dilakukan pendekatan metode dengan mengadopsi pola DSR.

4. Penjelasan Singkat Artefak

Tahapan ini menjelaskan secara singkat artefak dari aplikasi yang di rancang beserta komponen perancangannya.

5. Evaluasi

Aplikasi dievaluasi untuk menjelaskan hasil dengan bukti untuk memenuhi kriteria pengguna.

6. Diskusi

Bagian ini di diskusikan seberapa berhasil aplikasi yang dirancang dapat menjadi solusi masalah yang dijelaskan sebelumnya beserta saran untuk perbaikan ke depan.

7. Kesimpulan

Menyajikan kontribusi penelitian dan menjelaskan mengapa kontribusi dalam penelitian ini penting.

\section{TINJAUAN PUSTAKA}

Dalam sesi ini menjelaskan secara singkat penelitian yang terkait dengan penelitian ini, teori singkat PaaS yang menjadi bagian dari layanan komputasi awan, dan teori singkat pada model DSR.

\subsection{Penelitian yang Terkait}

Pariwisata dewasa ini sudah menjadi sektor industri yang menyumbang devisa bagi negara, sehingga teknologi informasi sudah merambah ke sektor industri pariwisata seperti pengembangan alat bantu untuk pengambilan keputusan menentukan lokasi wisata (Santiary, dkk., 2018). Selain itu ada penelitian yang mengukur tingkat niat penggunaan aplikasi seluler untuk perjalanan wisata yang mana hasil nya nanti digunakan untuk mengembangkan aplikasi perjalanan wisata secara berkelanjutan (Choi, Wang \& Sparks, 2019), fokus pada industri perhotelan dan pariwisata dengan memanfaatkan teknologi seluler dengan agenda penelitian yang mengusulkan untuk memandu penelitian selanjutnya tentang penggunaan teknologi seluler di industri perhotelan dan pariwisata (Law, Chan \& Wang, 2018). Sebuah penelitian memberikan penilaian 
tentang bagaimana konsumen menggunakan aplikasi untuk mengarahkan para pelanggan mengunjungi tempat wisata, untuk mengeksplorasi niat pelanggan digunakan Technology Acceptance Model (TAM) dalam mengadopsi aplikasi pariwisata (Kuo dkk., 2019).

Impelementasi penelitian secara waktu nyata layanan aplikasi untuk informasi wisata seperti aplikasi restoran untuk wisata kuliner yang berbasis website (Pandean \& Hansun, 2018), aplikasi berbasis mobile untuk membantu pengguna dalam mendapat rekomendasi kuliner berdasarkan perbandingan antara Analytic Hierarchy Process (AHP) dengan Hybrid AHP (Dewi, Hanggara \& Pinandito, 2018), bahkan dengan teknologi informasi kita bisa memanfaatkan mode web crawling untuk mengumpulkan informasi wisata kuliner (Hanifah \& Nurhasanah, 2018).

Dari semua penjelasan penelitian yang sebelumnya bisa diperoleh gambaran bahwa pembahasan mengenai aplikasi yang mendukung pariwisata merupakan tantangan penelitian yang sangat menarik untuk dilakukan. Maka dalam penulisan ini penelitian yang dilakukan dengan merancang dan membangun aplikasi yang berbasis Android serta memanfaatkan media PaaS dan Google Maps dalam proses menyimpan informasi yang di kumpulkan dan pencarian lokasi wisata, kemudian metode DSR dimanfaatkan dalam penelitian ini sebagai pedoman dalam membangun dan mengevaluasi jejak digital.

\subsection{Platform as a Service}

Komputasi awan memerlukan strategi pendekatan untuk kinerja maupun fungsi perusahaan (Kathuria, dkk., 2018), serta nilai - nilai dari transformasi yang mendukung performa komputasi awan (Giessmann \& Legner, 2016). Pengawasan ketika merancang dan mengevaluasi dalam layanan komputasi awan dianggap perlu untuk mendukung keputusan dalam faktor - faktor tertentu (Lansing, Benlian \& Sunyaev, 2018).

Model layanan dari komputasi awan ada tiga layanan, dalam penelitian ini digunakan Platform as a Service (PaaS) yang mana menawarkan pengembangan aplikasi, layanan PaaS menggabungkan atribut yang bervariasi antara lain skalabilitas, keandalan dan keamanan. PaaS mempunyai fasilitas bawaan layanan web dan basis data yang terintegrasi (Gonçalves \& Ballon, 2011; Coccoli, dkk., 2015).

Contoh dari layanan PaaS seperti Google App Engine yang bermanfaat dalam mengembangkan aplikasi web, selain itu layanan PaaS yang lain adalah IBM Bluemix yang fungsinya mirip Google App Engine (Kim, dkk., 2016).

IBM Bluemix mendukung layanan mobile cloud yang di dalamnya terdapat fasilitas aplikasi mobile cloud, pengembangan data, penyimpanan file, authentifikasi, notifikasi semuanya itu telah tersedia dan mudah digunakan (Gheith, dkk., 2016).

\subsection{Design Science Research}

Design Sicence Research (DSR) merupakan permodelan dalam bingkai kerja yang dimanfaatkan dalam penelitian ini, model dari bingkai kerja ini bertujuan untuk pemecahan masalah yang membangun dan mengevaluasi jejak digital secara waktu nyata (Carcary, 2011). Selain itu model kerja ini melibatkan variabel yang mempertimbangkan desain dan utilitas desain (Gill \& Hevner, 2013; Hevner \& Chatterjee, 2010), serta menentukan karakter variabel yang dievaluasi (Venable, PriesHeje \& Baskerville, 2016). DSR dapat memberikan gambaran kerangka Business Intelligence (BI) dalam panyebarannya di komputasi awan (Sangupamba Mwilu, Comyn-Wattiau \& Prat, 2016). DSR membantu peneliti dalam memberikan pedoman merumuskan pertanyaan ketika melakukan perencanaan penelitian (Thuan, Drechsler \& Antunes, 2019; Alismail, Zhang \& Chatterjee, 2017)

\section{HASIL DAN PEMBAHASAN}

Di tahapan ini dijelaskan artefak dari aplikasi yang dirancang dengan komponen perancangannya. Kemudian masuk dalam tahap evaluasi hasil dan diskusi.

\subsection{Perancangan Aplikasi Bergerak}

Pada Gambar 1 merupakan gambaran use case diagram aplikasi yang dirancang untuk memperlihatkan model layanan yang dinyatakan dalam sistem, kemudian dalam use case diagram terlihat ada dua aktor yaitu Admin yang merancang, membangun dan mengatur aplikasi yang di buat dan Pengguna yang mempunyai peran sebagai pihak yang berinteraksi dengan sistem atau menerima informasi dari sistem.

Dalam use case diagram pada aplikasi yang dirancang terdapat boundary system yang berfungsi sebagai tempat merepresentasi dari lingkup sistem yang dikembangkan, meskipun aktor dalam hal ini Admin dan Pengguna tetap berada di luar kotak.

Admin dapat mengakses semua halaman yang disajikan didalam menu aplikasi seperti input data beranda, beranda, input data tempat wisata, tempat wisata, input data tentang dan juga tentang.

Untuk Pengguna hanya dapat mengakses halaman beranda, tempat wisata, dan menu tentang, tetapi tidak bisa memasukkan data ke dalam sistem yang dibangun.

Activity Diagram dirancang agar dapat mem perlihatkan alur langkah demi langkah dalam proses. Activity diagram terdiri dari activity beranda, activity tempat wisata dan activity tentang. 


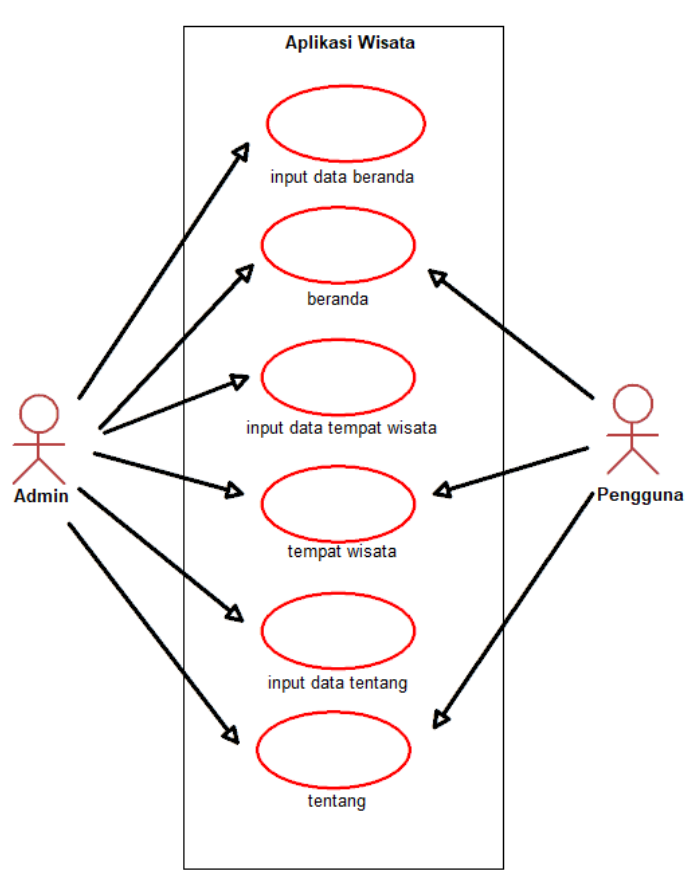

Gambar 1. Use case aplikasi wisata

Gambar 2 merupakan gambaran dari activity beranda yang menggambarkan aktifitas yang terjadi pada menu beranda.

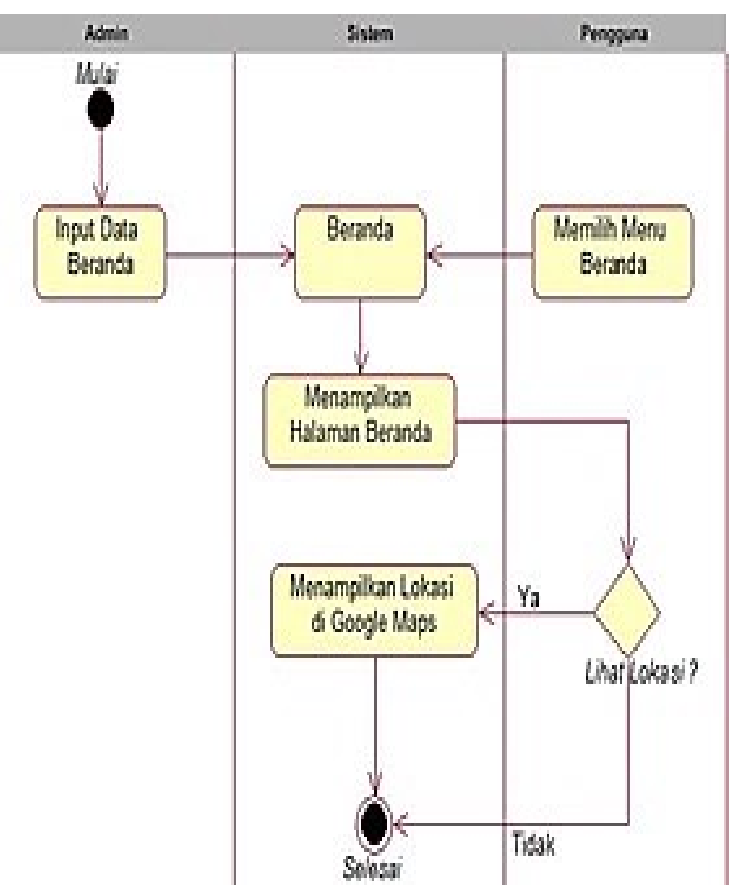

Gambar 2. Activity Beranda

Gambar 3 merupakan gambar dari activity tempat wisata yang menggambarkan aktifitas yang terjadi pada menu tempat wisata. Gambar 4 merupakan gambar dari activity tentang yang menggambarkan aktifitas yang terjadi pada menu tentang.
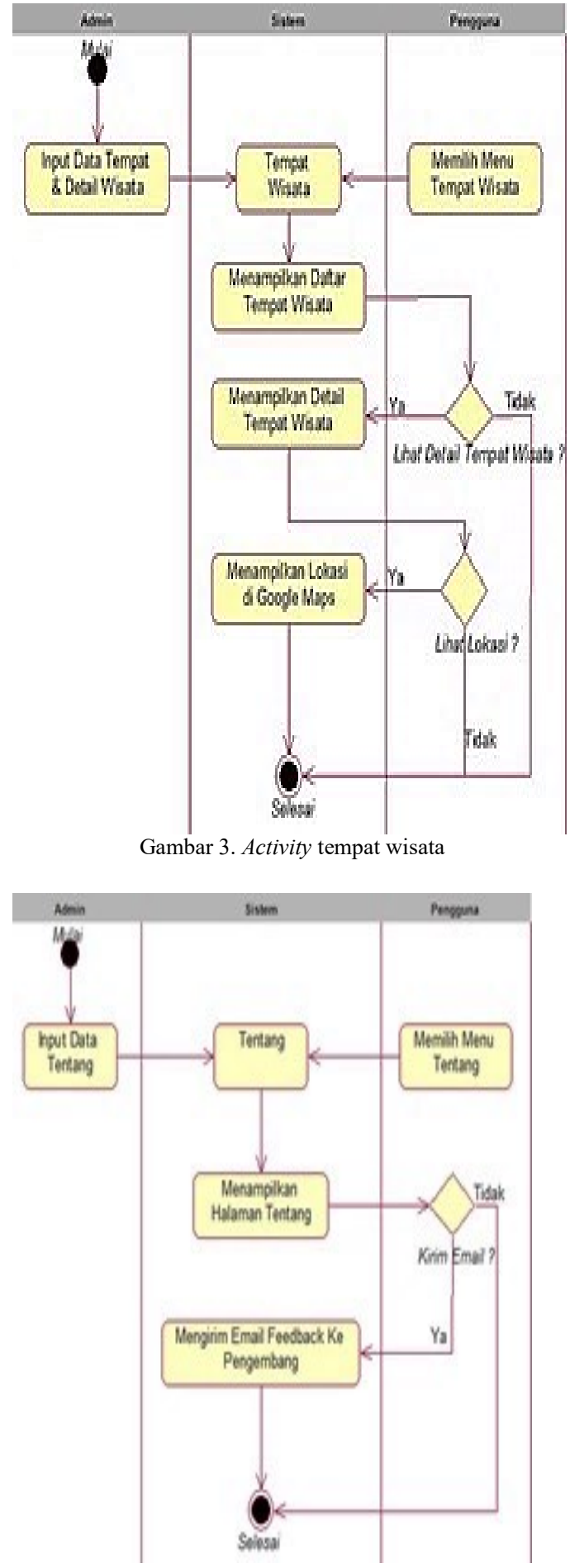

Gambar 4. Activity tentang

Selanjutnya dirancang diagram sekuensial yang menggambarkan interaksi yang disusun berdasarkan urutan waktu. Sequence diagram yang dibuat terdiri dari sequence beranda admin, sequence tempat wisata admin, sequence tentang admin, sequence beranda pengguna, sequence tempat wisata penggunan, dan sequence tentang pengguna.

Gambar 5 merupakan gambaran sequence diagram dari pola aktor Admin pada menu beranda. 


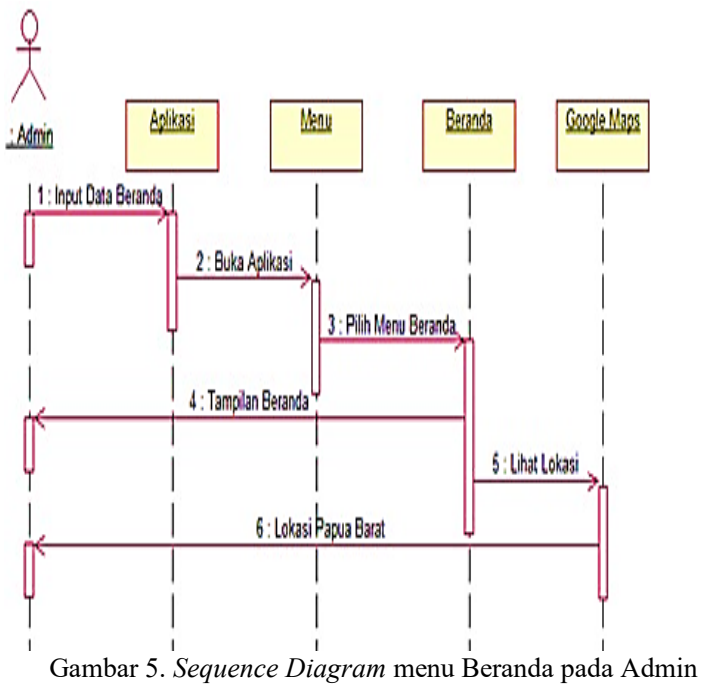

Gambar 6 merupakan gambar dari sequence diagram admin yang menggambarkan perilaku actor pada menu tempat wisata.

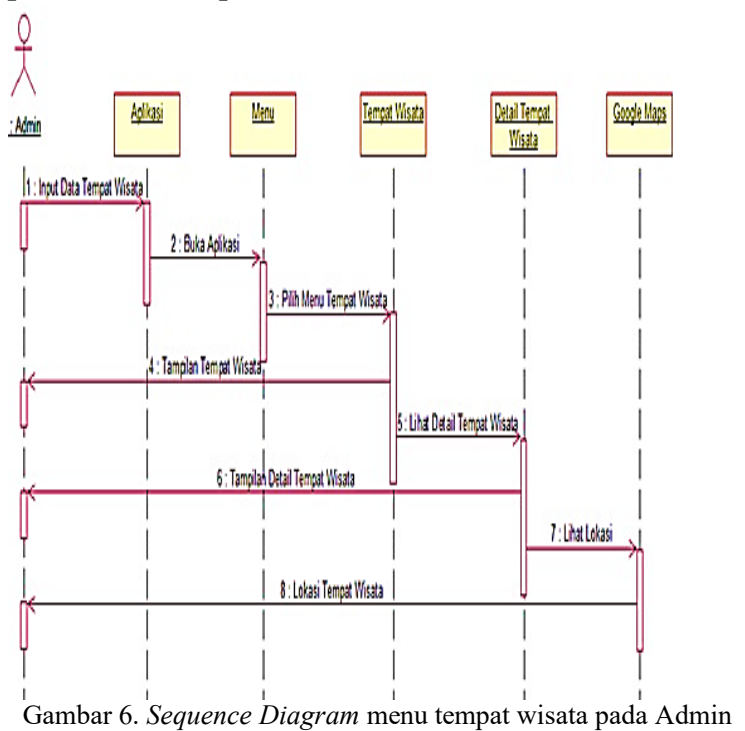

Gambar 7 merupakan pola dari sequence diagram seorang pengguna yang menggambarkan perilaku actor pada menu tempat wisata.

\subsection{Pembuatan Tampilan Antarmuka}

Dalam tahapan ini aktivitas yang dilakukan antaralain membuat tampilan menu navigasi, tampilan menu baranda, tampilan menu tempat wisata, tampilan detail tempat wisata dan tampilan tentang yang memuat informasi pembuatan aplikasi. Pembuatan aplikasi ini melalui aplikasi layanan Bluemix. Gambar 8 adalah proses pembuatan tampilan menu beranda menggunakan IBM Bluemix.

Setelah semua menu telah di buat tahapan selanjutnya mengatur nama dari aplikasi yang dibuat, penjelasan aplikasi, kunci Google API untuk mendapat layanan google maps serta mengatur yang dasar seperti warna latar belakang aplikasi yang dibuat.

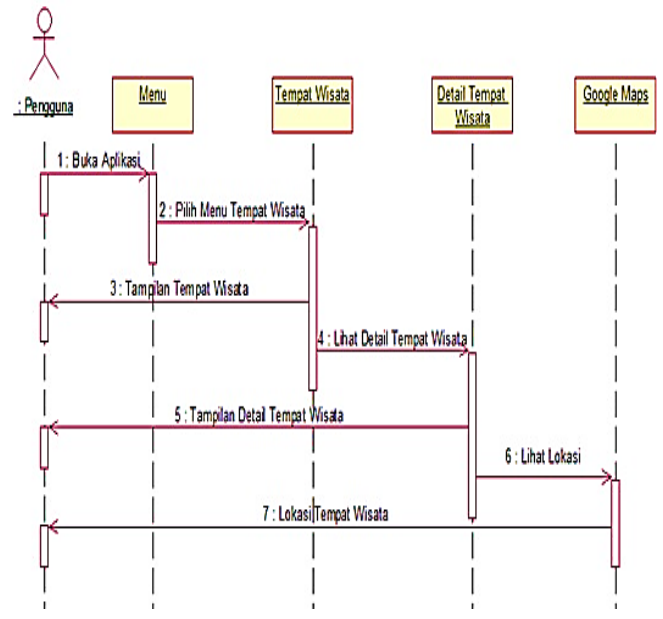

Gambar 7. Sequence Diagram menu tempat wisata pada Pengguna

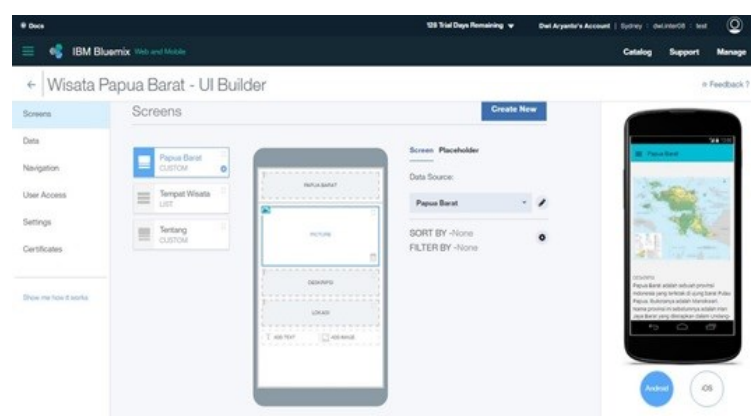

Gambar 8. Proses Pembuatan Tampilan Menu Aplikasi

Selanjutnya aplikasi di generate, ada tiga sumber kode yang dapat dipakai antara lain Android, iOS(Objective - C) dan iOS (Swift). Dalam penelitian ini aplikasi di generate menjadi aplikasi Android. Setelah aplikasi selesai dibuat dengan layanan IBM Bluemix selanjutnya tampilan splash screen dibuat dengan Android Studio.

Pada Gambar 9 menggambarkan hasil tampilan beranda pada aplikasi yang dibuat, beranda memuat informasi mengenai provinsi papua barat beserta peta lokasi pada layanan peta google maps.

Untuk hasil menu tempat wisata yang berisi tempat-tempat wisata yang berada di provinsi papua barat disajikan dalam Gambar 10.

\subsection{Evaluasi Hasil dan Diskusi}

Seperti yang dijelaskan metode DSR mempunyai tujuh langkah dan pada sub bahasan ini masuk pada tahap lima dan enam yaitu evaluasi dan diskusi. Tahapan evaluasi bertujuan untuk melalukan pengujian pada perangkat aplikasi yang di bangun, agar dapat diketahui sejauh mana aplikasi ini sesuai dengan kebutuhan. Tahapan ini dibuatlah kuisioner untuk mengetahui tingkat kepuasan pengguna akhir terhadap aplikasi yang dibuat.

Tabel 1 merupakan bentuk dari pertanyaanpertanyaan dari kuisioner yang disebarkan kepada tiga kelompok masyarakat antara lain pegawai dinas 
pariwisata, masyarakat umum dan mahasiswa dengan jumlah partisipan 28 orang.

Tabel 1. Pertanyaan untuki tingkat kepuasan pengguna

\begin{tabular}{cl}
\hline nomor & \multicolumn{1}{c}{ pertanyaan } \\
\hline 1 & $\begin{array}{l}\text { Bagaimana pendapat anda apabila ada aplikasi } \\
\text { android tentang tempat wisata yang berada di } \\
\text { provinsi papua barat? }\end{array}$ \\
2 & $\begin{array}{l}\text { Menurut anda bagaimana desain pada aplikasi ini? } \\
3\end{array}$ \\
4 & $\begin{array}{l}\text { Menurut anda bagaimana penggunaan aplikasi ini? } \\
\text { dalam aplikasi ini? }\end{array}$ \\
5 & $\begin{array}{l}\text { Apakah anda terbantu dengan adanya aplikasi } \\
\text { wisata papua barat ini? }\end{array}$ \\
6 & $\begin{array}{l}\text { Apakah anda puas dengan fitur yang disediakan } \\
\text { aplikasi ini? }\end{array}$ \\
7 & $\begin{array}{l}\text { Bagaimana pendapat anda tentang keseluruhan } \\
\text { fungsi aplikasi ini? } \\
\text { Menurut anda apakah aplikasi ini dapat berguna } \\
\text { sebagai sarana promosi tempat wisata yang berada } \\
\text { di provinsi papua barat? } \\
\text { Apakah aplikasi ini sudah layak digunakan olah } \\
\text { masyarakat umum? }\end{array}$ \\
\hline
\end{tabular}

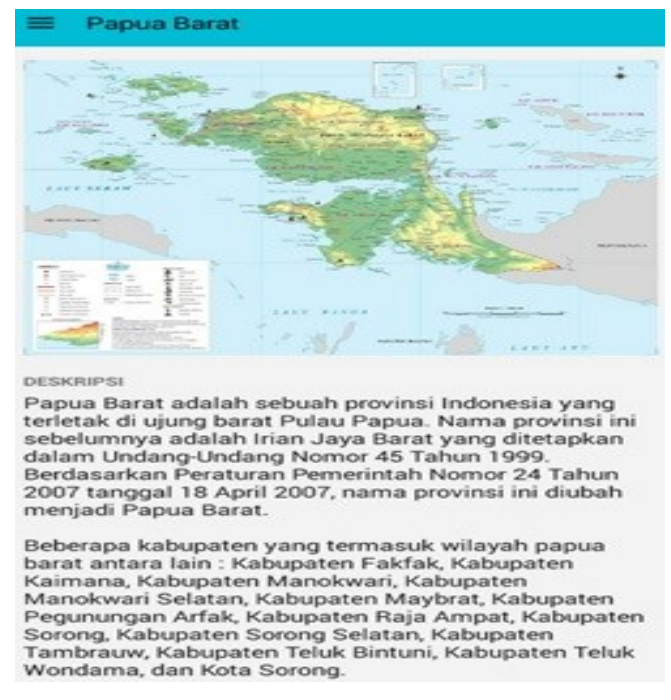

Gambar 9. Menu Beranda Aplikasi

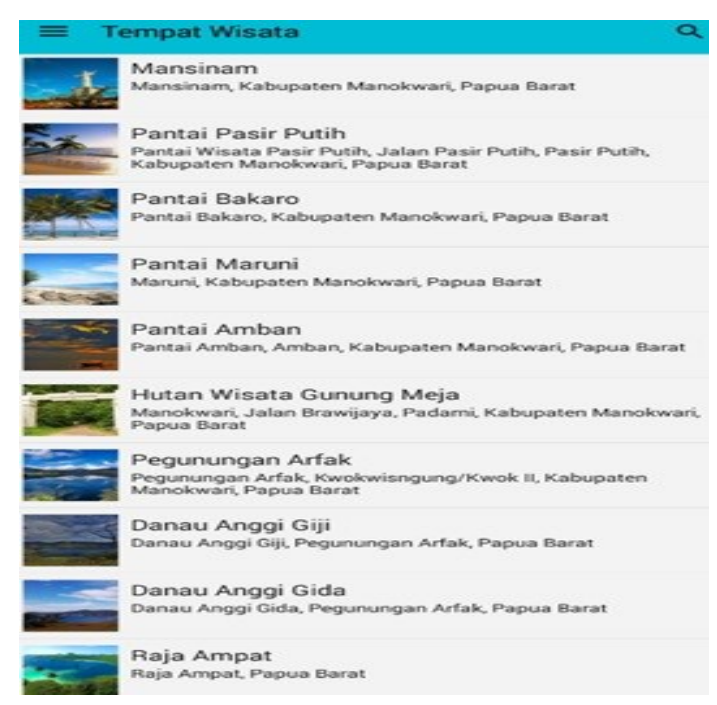

Gambar 10. Menu Tempat Wisata
Berdasarkan kuisioner yang dibagikan maka hasil kalkulasi dan rekapan nya dapat di lihat seperti pada Tabel 2.

\begin{tabular}{|c|c|c|c|c|c|}
\hline \multirow{2}{*}{$\begin{array}{c}\text { nomor } \\
\text { pertanyaan }\end{array}$} & \multicolumn{4}{|c|}{ pilihan jawaban } & \multirow[t]{2}{*}{ total partisipan } \\
\hline & $\mathbf{A}$ & B & $\mathbf{C}$ & D & \\
\hline 1 & 17 & 11 & 0 & 0 & 28 \\
\hline 2 & 9 & 19 & 0 & 0 & 28 \\
\hline 3 & 10 & 17 & 1 & 0 & 28 \\
\hline 4 & 7 & 11 & 8 & 2 & 28 \\
\hline 5 & 14 & 11 & 3 & 0 & 28 \\
\hline 6 & 5 & 17 & 6 & 0 & 28 \\
\hline 7 & 6 & 18 & 3 & 1 & 28 \\
\hline 8 & 14 & 13 & 1 & 0 & 28 \\
\hline 9 & 11 & 13 & 4 & 0 & 28 \\
\hline
\end{tabular}

Dalam Tabel 2 dapat dilihat hasil bahwa total pilihan A sebesar 93, B sebesar 130, C sebesar 26 dan D sebesar 3 bila di konversi ke persen maka didapatkan hasil 36,9\% memilih A, 51,6\% memilih B, 10,3\% memilih C dan D sebesar 1,2\%.

Hasil Kuisioner diketahui para pengguna akhir memilih pilihan B yang mewakili pilihan setuju sebesar 51,6\% dengan kata lain pengguna akhir setuju apabila aplikasi ini dapat dipakai untuk mempromosikan pariwisata provinsi papua barat.

Tinjauan sisi desain dan penggunaan aplikasi ini para responden juga menjawab bahwa desainnya bagus dan mudah di operasikan.

Untuk informasi yang disajikan dan kemudahan mendapatkan informasi pariwisata di Papua Barat para responden menjawab sangat terbantu dan informasi yang disajikan sudah bagus serta sesuai yang dibutuhkan wisatawan.

Para responden puas dengan fitur dalam aplikasi yang dibuat. Kemudian para responden juga berpendapat bahwa fungsi pada aplikasi ini juga baik.

Untuk promosi pariwisata aplikasi ini dianggap sangat berguna oleh para responden dan layak digunakan oleh masyarakat yang ingin mengetahui mengenai pariwisata di provinsi papua barat.

\section{KESIMPULAN}

Berdasarkan hasil dan diskusi yang telah dilakukan dalam penelitian tentang proses rancang dan bangun sebuah aplikasi untuk layanan informasi pariwisata di Provinsi Papua Barat, maka model DSR pada bidang pengembangan Sistem Informasi digunakan sebagai alat untuk menuntun dalam mengerjakan penelitian ini.

Dalam evaluasi yang telah dilakukan terlihat bahwa hasil penyebaran kusioner bagi 28 responden untuk tingkat kepuasan pemanfaatan aplikasi ini sebanyak 36,9 \% Sangat Setuju , 51,6\% mengatakan Setuju, 10,3\% menyatakan Cukup dan 1,2\% reponden mengatakan Kurang. Maka aplikasi ini dapat digunakan sebagai sarana alternatif untuk promosi dan mencari informasi pariwisata di Provinsi Papua Barat.

Penambahan fitur jenis wisata seperti wisata kuliner dan budaya, bisa menjadi pengembangan 
penelitian kedepan. Selain itu, penambahan fitur aplikasi yang dapat mengambil keputusan untuk destinasi wisata yang lengkap sesuai dengan kebutuhan wisatawan sangat perlu dikembangkan dalam penelitian selanjutnya.

\section{DAFTAR PUSTAKA}

AGUSTINA, E.R. \& ACHMAD, F., 2019. Perancangan Spesifikasi Keamanan Kontrol Akses pada Aplikasi Layanan Informasi di Lingkungan Instansi Pemerintah. Jurnal Teknologi Informasi dan Ilmu Komputer, 6(2), pp.195-200.

ALISMAIL, S., ZHANG, H. \& CHATTERJEE, S., 2017. A Framework for Identifying Design Science Research Objectives for Building and Evaluating IT Artifacts. In: A. Maedche, J. vom Brocke and A. Hevner, eds. Designing the Digital Transformation, Lecture Notes in Computer Science. Springer International Publishing.pp.218230.

CARCARY, M., 2011. Design Science Research: The Case of the IT Capability Maturity Framework (IT CMF) by Academic Conferences and publishing International Issuu. The Electronic Journal of Business Research Methods, 9(2), pp.109-118.

CHOI, K., WANG, Y. \& SPARKS, B., 2019. Travel app users' continued use intentions: it's a matter of value and trust. Journal of Travel \& Tourism Marketing, 36(1), pp.131-143.

COCCOLI, M., MARESCA, P., STANGANELLI, L. \& GUERCIO, A., 2015. An experience of collaboration using a PaaS for the smarter university model. Journal of Visual Languages \& Computing, 31, pp.275-282.

DEWI, R.K., HANGGARA, B.T. \& PINANDITO, A., 2018. A Comparison Between AHP and Hybrid AHP for Mobile Based Culinary Recommendation System. International Journal of Interactive Mobile Technologies (iJIM), 12(1), pp.133-140.

GHEITH, A., RAJAMONY, R., BOHRER, P., AGARWAL, K., KISTLER, M., EAGLE, B.L.W., HAMBRIDGE, C.A., CARTER, J.B. \& KAPLINGER, T., 2016. IBM Bluemix Mobile Cloud Services. IBM Journal of Research and Development, 60(23), pp. 7:1-7:12.

GIESSMANN, A. \& LEGNER, C., 2016. Designing business models for cloud platforms. Information Systems Journal, 26(5), pp.551579.

GILL, T.G. \& HEVNER, A.R., 2013. A FitnessUtility Model for Design Science Research. ACM Trans. Manage. Inf. Syst., 4(2), pp. 5:1-5:24.

GONÇALVES, V. \& BALLON, P., 2011. Adding value to the network: Mobile operators' experiments with Software-as-a-Service and Platform-as-a-Service models. Telematics and Informatics, 28(1), pp.12-21.

GREGOR, S. \& HEVNER, A.R., 2013. Positioning and Presenting Design Science Research for Maximum Impact. MIS Quarterly, 37(2), pp.337-355.

HANIFAH， R. \& NURHASANAH，I.S., 2018. Implementasi Web Crawling untuk Mengumpulkan Informasi Wisata Kuliner di Bandar Lampung. Jurnal Teknologi Informasi dan Ilmu Komputer, 5(5), pp.531536.

HEVNER, A. \& CHATTERJEE, S., 2010. Design Science Research in Information Systems. In: A. Hevner and S. Chatterjee, eds. Design Research in Information Systems: Theory and Practice, Integrated Series in Information Systems. [online] Boston, MA: Springer US.pp.9-22. Tersedia di: $<$ https://doi.org/10.1007/978-1-4419-56538_2> [Diakses 19 Jun. 2019].

KATHURIA, A., MANN, A., KHUNTIA, J., SALDANHA, T.J.V. \& KAUFFMAN, R.J., 2018. A Strategic Value Appropriation Path for Cloud Computing. Journal of Management Information Systems, 35(3), pp.740-775.

KIM, M., MOHINDRA, A., MUTHUSAMY, V., RANCHAL, R., SALAPURA, V., SLOMINSKI, A. \& KHALAF, R., 2016. Building scalable, secure, multi-tenant cloud services on IBM Bluemix. IBM Journal of Research and Development, 60(2-3), pp.8:1$8: 12$.

KUO, T.-S., HUANG, K.-C., NGUYEN, T.Q. \& NGUYEN, P.H., 2019. Adoption of mobile applications for identifying tourism destinations by travellers: an integrative approach. Journal of Business Economics and Management, 20(5), pp.860-877.

LANSING, J., BENLIAN, A. \& SUNYAEV, A., 2018. "Unblackboxing" Decision Makers' Interpretations of IS Certifications in the Context of Cloud Service Certifications. Journal of the Association for Information Systems, [online] 19(11). Tersedia di: $<$ https://aisel.aisnet.org/jais/vol19/iss11/3>.

LAW, R., CHAN, I.C.C. AND WANG, L., 2018. A comprehensive review of mobile technology use in hospitality and tourism. Journal of Hospitality Marketing \& Management, 27(6), pp.626-648.

PANDEAN, S.S. \& HANSUN, S., 2018. Aplikasi WEB untuk Rekomendasi Restoran Menggunakan Weighted Product. Jurnal Teknologi Informasi dan Ilmu Komputer, 5(1), pp.87-94.

RANTELINGGI, P.H. \& DJANALI, S., 2015. Kinerja Protokol Routing pada Lingkungan 
Wireless Mesh Network dengan Combined Scalable Video Coding. JUTI: Jurnal Ilmiah Teknologi Informasi, 13(1), pp.86-94-94.

RANTELINGGI, P.H., PAIKI, F.F. \& RANTELOBO, K., 2017. Performance of routing protocol in MANET with combined scalable video coding. In: 2017 4th International Conference on Electrical Engineering, Computer Science and Informatics (EECSI). 2017 4th International Conference on Electrical Engineering, Computer Science and Informatics (EECSI). pp. $1-4$.

SANGUPAMBA MWILU, O., COMYNWATTIAU, I. \& PRAT, N., 2016. Design science research contribution to business intelligence in the cloud - A systematic literature review. Future Generation Computer Systems, 63, pp.108-122.

SANTIARY, P.A.W., CIPTAYANI, P.I., SAPTARINI, N.G.A.P.H. \& SWARDIKA,
I.K., 2018. Sistem Pendukung Keputusan Penentuan Lokasi Wisata dengan Metode Topsis. Jurnal Teknologi Informasi dan Ilmu Komputer, 5(5), pp.621-628.

SHIHAB, M.R. \& MURTADHO, A., 2011. Analisis Situs E-Tourism Indonesia: Studi Terhadap Persebaran Geografis, Pengklasifikasian Situs Serta Pemanfaatan Fungsi dan Fitur. Jurnal Sistem Informasi, 7(1), pp.13-24.

THUAN, N., DRECHSLER, A. \& ANTUNES, P., 2019. Construction of Design Science Research Questions. Communications of the Association for Information Systems, [online] 44(1). Tersedia di: $<$ https://aisel.aisnet.org/cais/vol44/iss1/20>.

VENABLE, J., PRIES-HEJE, J. \& BASKERVILLE, R., 2016. FEDS: a Framework for Evaluation in Design Science Research. European Journal of Information Systems, 25(1), pp.77-89. 